\title{
Rare case of mandibular osteosarcoma: Clinical, imaging and pathological aspects
}

\author{
Regis Manzini ${ }^{1,2}$, Idiberto José Zotarelli Filho ${ }^{1,2 *}$, Wesley Antonio Galhardo Fornazari ${ }^{1,2}$, Tamiris Gomes Mazza da Cruz ${ }^{1,2}$, Luiz Gustavo \\ Rodrigues Capela ${ }^{1}$, Moniele Matos Cadamuro ${ }^{1}$ and Elias Naim Kassis ${ }^{1,2}$ \\ ${ }^{1}$ Unorp - University Center North Paulista - São José do Rio Preto - SP, Brazil \\ ${ }^{2}$ Unipos - Post graduate and continuing education, Street Ipiranga, 3460, São José do Rio Preto SP, Brazil
}

\begin{abstract}
The annual incidence of new cases of osteosarcoma (OS) affects about 0.7 million people, is more frequent in males and in the third and fourth decade of life the average age of highest incidence. Since the involvement of maxillofacial region is rare, around $6.0 \%$ of all cases of OS. The aim of this study was to report a case of osteosarcoma in the mandible, describing its clinical, imaging and histopathological. Patient female, 20 years old, leucoderma, searched for referral to a specialized clinic in Surgery and Traumatology Oral and maxillofacial. Increased volume of the anterior mandible region with a history of 3-4 months has been presented in the case below. Surgical excision margin of safety is the main treatment for OS with local recurrence in approximately $60 \%$ of patients, usually during the first year after treatment. Survival rates at 5 years are reported with an average of $43 \%$ for OS gnathic. It concludes that OS is an aggressive and rare cancer in maxillofacial region, where surgical excision is the best treatment, with high probability of relapse in the first year.
\end{abstract}

\section{Introduction}

The osteosarcoma (OS) represent $20 \%$ of all sarcomas, including preexisting bone abnormalities, previous trauma, osteogenesis imperfect and others. The annual incidence of new cases affects about 0.7 million people, is more frequent in males [1] and in the third and fourth decade of life the average age of highest incidence [1-3]. Furthermore, the occurrence of OS [4] is larger long bones, representing $60 \%$ of all malignant tumors [5], with an incidence of 1: 100,000 [6]. Since the involvement of maxillofacial region is rare, around $6.0 \%$ of all cases of OS.

Metastases of OS are most commonly observed in lungs or bones [7]. Metastasis in the oral cavity and jaw are rare, about 1\% [8], few well-documented cases of metastatic THE oral mucosa are known to 2015 [8]. However, as gap information, because of the relative rarity of this condition, no treatment guidelines based on clearly defined evidence for these tumors.

The most common signs and symptoms associated with OS in the jaw are persistent pain, increased volume and paresthesia $[6,9]$. The OS are shown as osteoblastic or osteolytic lesions with periosteal reaction in X-rays, and the findings patológicosrevelam osteoid tissue produced by the tumor, with a high density of malignant cells. The histological types are known chondroblastic (41\%), osteoblastic (33\%) and fibroblast $(26 \%)[4,10]$. According to some case series, $50 \%$ of the OS in the jaw are condroblásticos, and this type is associated with a better prognosis than other histological types $[3,11]$.

Several authors say that the OS of the maxilla as a specific entity with different clinical behavior of other skeletal bones [1-3,12]. Unlike the OS of long bones, head and neck occur most commonly in the third and fourth decades of life without bias regarding gender [1-3,12,13]. Risk factors have been attributed to the cause of the OS; the rapid bone growth is one of them [14]. Craniofacial are also associated with older patients with Paget's disease of skeletal [15], fibrous dysplasia and bone as a late sequelae of craniofacial irradiation [16].

The aim of this study was to report a case of osteosarcoma in the mandible, describing it's clinical, imaging and histopathological.

\section{Case report}

A female patient of 20 years with leucoderma was presented with referral to a specialized clinic in oral and maxillofacial surgery and traumatology. The patient presented had an increased volume of the anterior mandible region for 3-4 months. Initially, there was no pain, however, after the first surgical exploration the case evolved with pain, hyperthermia site, tooth mobility, paresthesia in the region, hypersalivation and loss of appetite.

The intraoral examination revealed increased volume of firm consistency extending from the region of 42 to 35 , involving the arch, vestibular fornix area and floor of the mouth of the region. Patient was diagnosed with ulcerated lesion in tooth at displacement region between 32 and 33 (Figure 1). A panoramic radiograph revealed a mixed aspect area of irregular and indefinite edges (Figure 2). In computed tomography a tumor mass of aggressive aspect involving the alveolar part can be observed, with expansion of buccal and lingual cortical bone, followed by peripheral bone destruction and irregular high and low density areas (FigureS 3 and 4 ).

Correspondence to: Idiberto José Zotarelli Filho, Unipos-Post Graduate and Continuing Education, Street Ipiranga, 3460, São José do Rio Preto SP, 15020-040, Brazil, Tel: +55(17) 98166-6537, +55(17) 98803-7459; E-mail: m.zotarelli@gmail.com

Keywords: osteosarcoma, maxillofacial, young patient

Received: June 04, 2015; Accepted: July 22, 2015; Published: July 25, 2015 

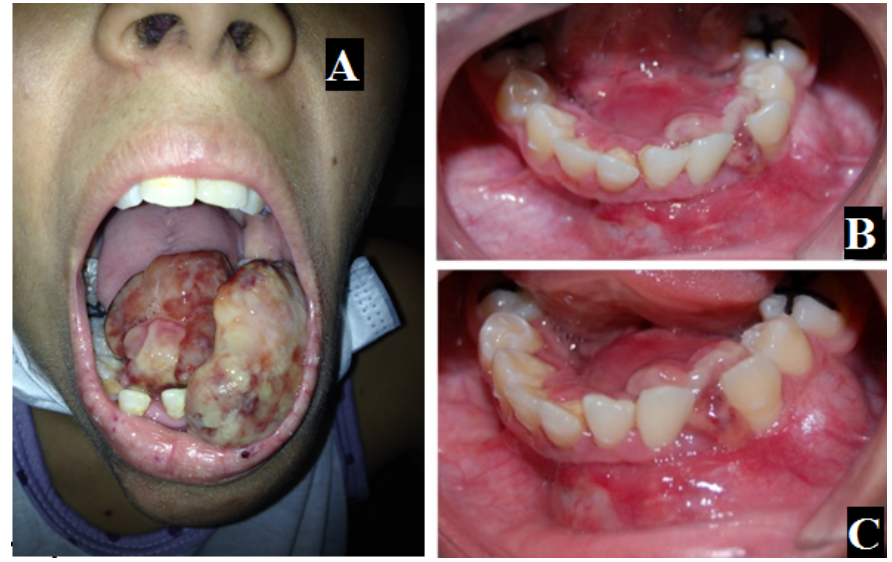

Figure 1. A: Front extra-oral photography showing the severity of osteosarcoma, B and $\mathrm{C}$ : intra oral photos showing the volumetric increase in mandibual region with bicortical bulging and ulceration.
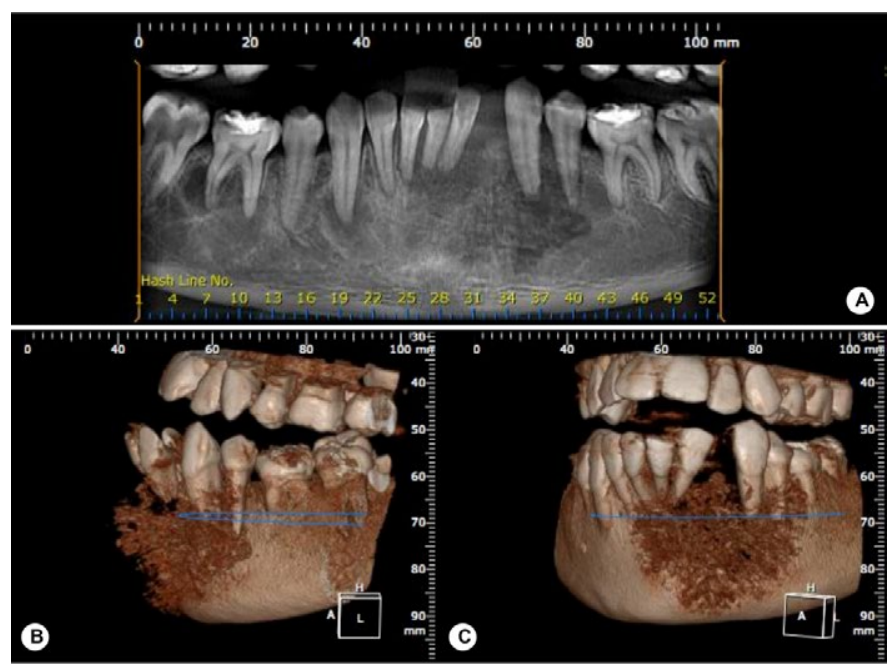

Figure 2. A: Panoramic image showing a mixed aspect area of irregular and undefined edges in the mandibular anterior region and $\mathrm{B}$ and $\mathrm{C}: 3 \mathrm{D}$ reconstructions.

Incisional biopsy was then performed and the harvested material sent to pathology analysis. Histologically, the tumor showed diffuse production of osteoid tissue and chondroid. Immunohistochemical studies revelaramreações positive for S-100 proteins, AML and for Ki-67 and negative for CD 34, desmin and myogenin. The lesion was then diagnosed with OS chondroblastic and the patient was referred to an oncologist (Figure 6). In postoperative of surgical manipulation, extensive tumor of rapid growth, firm consistency and reddish with leucoplásicos focuses emerged in manipulated region. It then carried out the mandibular rececção pacial with graft reconstruction fibula (Figure 7).

\section{Discussion}

The affects the head and neck in about $10 \%$ of cases. The jaw, as in this case, and the jaw are oslocais most often affected, followed by sinus [17]. The lesions usually have the same behavior reported by the patient, manifesting as a swelling or mass of the jaw or cheek, with or without paresthesia and pain; dental symptoms are less common [18].

The emergence of this injury the 20 -year-old goes against the literature that presents higher prevalence in the third and fourth
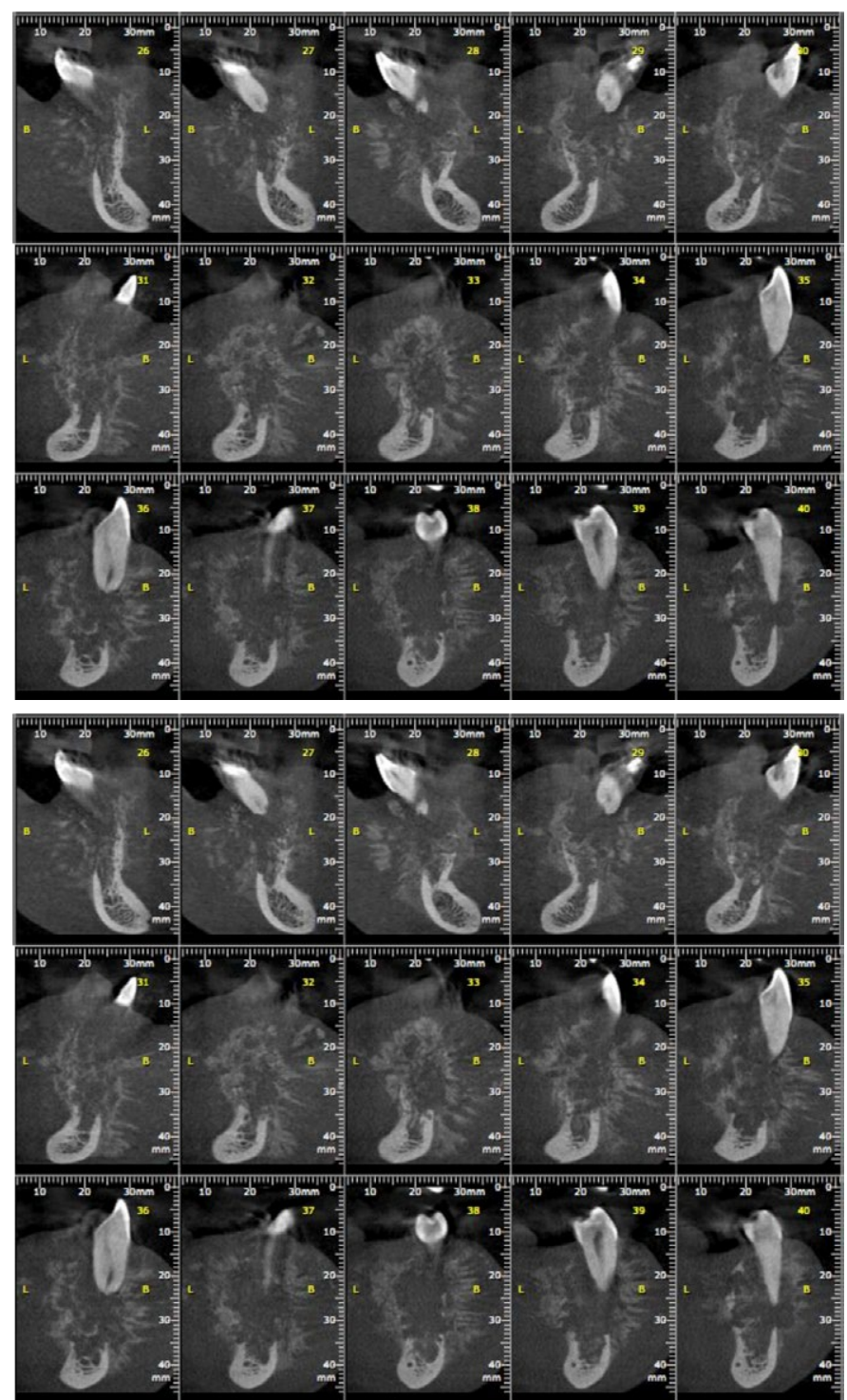

Figure 3. Tomographic slices of images detailing the areas affected by injury.

decades of life [2,3]. However, cases in younger patients have also been reported [19]. Because of this, the rapid bone growth is also attributed as a risk factor for the OS. This growth spurt occurs in younger stage and growth centers of the bones are the most affected areas, so the higher incidence of this type of injury in metaphyses of long bones [20].

The lesion was considered as primary, as the patient did not have any predisposing factors known in the literature, such as Paget's disease, previous exposure to radiation, fibrous dysplasia $[15,16]$. And clinically, the tumor was found to be the main type previously described [15]. The aggressiveness of the lesion indicated by its evolutionary history 3-4 months is amazing when evaluated the degree of bone destruction in imaging, however, it is reported by other authors as characteristic of this pathology [15].

Radiographically, the lesion showed mixed with standard osteogenic and osteolytic described as a resultant radiation pattern of fine and irregular bone spicules of new bone tissue, which develop towards the outside of the lesion, producing the so-called "appearance of sun rays" [21,22]. Histologically, these snippets of osteoid tissue, a 


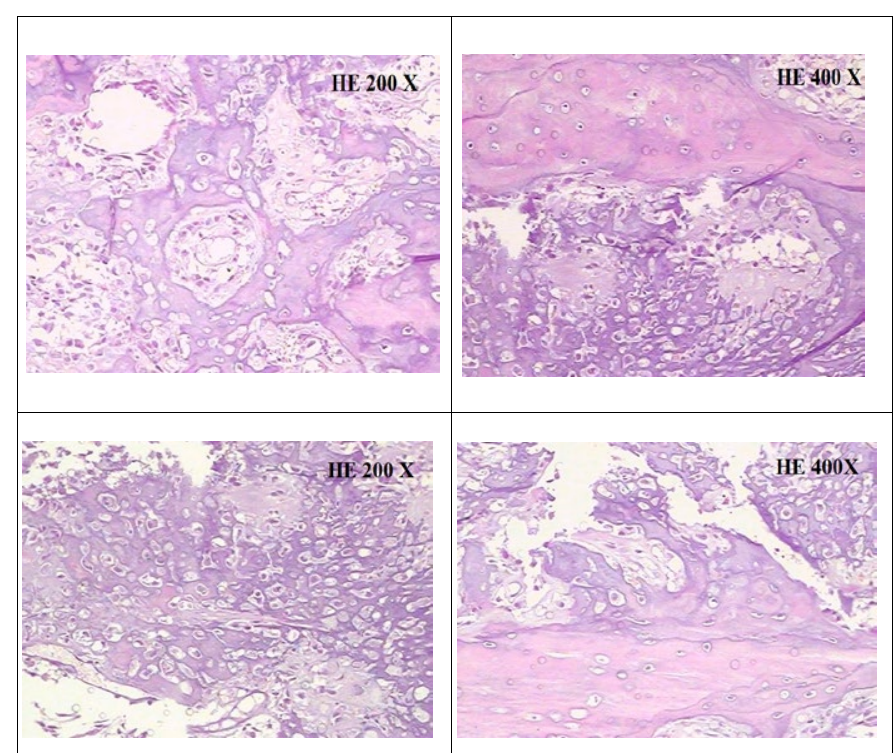

Figure 4. Histological microscopy showing mesenchymal cells fusiform disordered, not mineral bone matrix, eosinophilic, called esteoide, basophilic areas because of the mineralization of the osteoid matrix. Chondroid matrix areas were also observed.

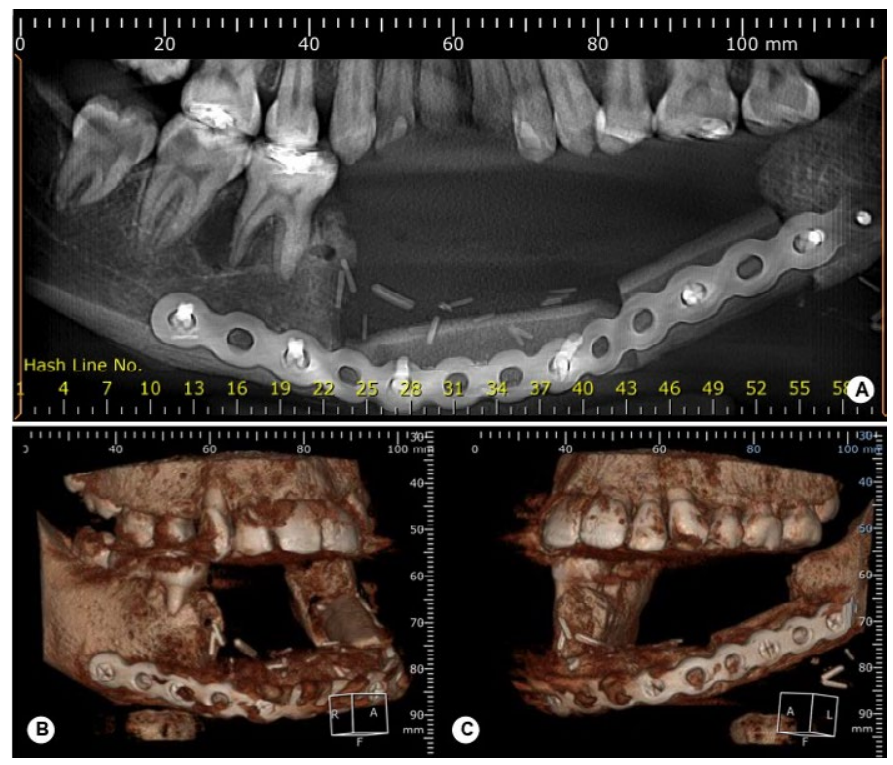

Figure 5. Tomographic scan showing the partial mandibular rececção immediate postoperative with immediate reconstruction with graft of fibula.

precursor of bone tissue, are given as distinguishing features of this type of injury.

Surgical excision margin of safety is the main treatment for OS [23-25] with local recurrence in approximately $60 \%$ of patients, usually during the first year after treatment. Survival rates at 5 years are reported average of $43 \%$ for OS gnathic [20,21].

\section{Conclusion}

It concludes that the OS is an aggressive and rare cancer in maxillofacial region, whose surgical excision is the best treatment, however, with high probability of relapse in the first year.

\section{Conflicts of interest}

The authors declare that they have no conflicts of interests.

\section{Acknowledgements}

The work was financially supported by Unipos - Postgraduate and Unorp - University Center North Paulista - São José do Rio Preto - SP, Brazil. We also thank the patient who agreed to participate in interviews and to all who contributed to the development and publication of results.

\section{References}

1. August M, Magennis P, Dewitt D (1997) Osteogenic sarcoma of the jaws: factors influencing prognosis. Int J Oral Maxillofac Surg 26: 198-204. [Crossref]

2. Delgado R, Maafs E, Alfeiran A, Mohar A, Barrera JL, et al. (1994) Osteosarcoma of the jaw. Head Neck 16: 246-252. [Crossref]

3. Bennett JH, Thomas G, Evans AW, Speight PM (2000) Osteosarcoma of the jaws: 30-year retrospective review. Oral Surg Oral Med Oral Pathol Oral Radiol Endod 90: 323-332. [Crossref]

4. Ajura AJ, Lau SH (2010) A retrospective clinicopathological study of 59 osteogenic sarcoma of jaw bone archived in a stomatology unit. Malays $J$ Pathol 32: 27-34. [Crossref]

5. Ong ST, Shim CK, Ng KH, Siar CH (2004) Osteosarcoma presenting as an aggressive nodular mass in the region of the mandible. J Oral Sci 46: 55-59. [Crossref]

6. Kassir RR, Rassekh CH, Kinsella JB, Segas J, Carrau RL, et al. (1997) Osteosarcoma of the head and neck: meta-analysis of nonrandomized studies. Laryngoscope 107: 5661. [Crossref]

7. Damron TA, Morganti C, Yang Y, Hojnowski L, Cherny R (2000) Metastasis of osteosarcoma to soft tissue. A case report. J Bone Joint Surg Am 82-82A: 1634-8. [Crossref]

8. Chen YK, Chen CH, Lin LM (2006) Soft-tissue metastasis of osteosarcoma to the submental vestibule. Int J Oral Maxillofac Surg 35: 1068-1071. [Crossref]

9. Cohen IJ (1993) Significant recent advances in the treatment of osteogenic sarcoma. Is $r$ J Med Sci 29: 748-753. [Crossref]

10. Fernandes R, Nikitakis NG, Pazoki A, Ord RA (2007) Osteogenic sarcoma of the jaw: a 10-year experience. J Oral Maxillofac Surg 65: 1286-1291. [Crossref]

11. Clark JL, Unni KK, Dahlin DC, Devine KD (1983) Osteosarcoma of the jaw. Cancer 51: 2311-2316. [Crossref]

12. Mardinger O, Givol N, Talmi YP, Taicher S (2001) Osteosarcoma of the jaw. The Chaim Sheba Medical Center experience. Oral Surg Oral Med Oral Pathol Oral Radiol Endod 91: 445-451. [Crossref]

13. Mark RJ, Sercarz JA, Tran L, Dodd LG, Selch M, et al. (1991) Osteogenic sarcoma of the head and neck. The UCLA experience. Arch Otolaryngol Head Neck Surg 117 761-766. [Crossref]

14. Garrington GE, Scofield HH, Cornyn J, Hooker SP (1967) Osteosarcoma of the jaws Analysis of 56 cases. Cancer 20: 377-391. [Crossref]

15. Brackenridge CJ (1979) A statistical study of sarcoma complicating Paget's disease of bone in three countries. Br J Cancer 40: 194-200. [Crossref]

16. Huvos AG, Woodard HQ, Cahan WG, Higinbotham NL, Stewart FW, et al. (1985) Postradiation osteogenic sarcoma of bone and soft tissues. A clinicopathologic study of 66 patients. Cancer 55: 1244-1255. [Crossref]

17. Frei C, Bornstein MM, Stauffer E, Iizuka T, Buser D (2004) Osteosarcoma of the maxilla and the maxillary sinus: a case report. Quintessence Int 35: 228-233. [Crossref]

18. Cutilli T, Scarsella S, Fabio DD, Oliva A, Cargini P (2011) High-grade chondroblastic and fibroblastic osteosarcoma of the upper jaw. Ann Maxillofac Surg 1: 176-180. [Crossref]

19. Laskar S, Basu A, Muckaden MA, D’Cruz A, Pai S, et al. (2008) Osteosarcoma of the head and neck region: lessons learned from a single-institution experience of 50 patients. Head Neck 30: 1020-1026. [Crossref]

20. Ludhani PM, Anathakrishnan R, Chandrasekar P, Muralidharan S (2013) Unusual case of chondroblastic osteosarcoma of the rib in an adult. Asian Cardiovasc Thorac Ann 22: 745-747. [Crossref] 
21. Chaudhary M, Chaudhary SD (2012) Osteosarcoma of jaws. J Oral Maxillofac Pathol 16: 233-238. [Crossref]

22. Lukschal LF, Lukschal Baeta RMB, Alvarenga RL, Rebello MCH (2013) Osteossarcoma em maxila: relato de caso. Rev Port Estomatol Med Dent Cir Maxilofac 54: 48-52.

23. Luna-Ortiz K, Villavicencio-Valencia V, Carmona-Luna T, Pasche P, MosquedaTaylor A (2010) Osteogenic sarcoma of the maxillary region in a Mexican mestizo population. J Craniofac Surg 21: 1709-1714. [Crossref]
24. Bentz BG, Singh B, Woodruff J, Brennan M, Shah JP, et al. (2004) Head and neck soft tissue sarcomas: a multivariate analysis of outcomes. Ann Surg Oncol 11: 619-628. [Crossref]

25. Rosenthal MA, Mougos S, Wiesenfeld D (2003) High-grade maxillofacial osteosarcoma: evolving strategies for a curable cancer. Oral Oncol 39: 402-404. [Crossref]

26. Murphey MD, Jelinek JS, Temple HT, Flemming DJ, Gannon FH (2004) Imaging of periosteal osteosarcoma: radiologic-pathologic comparison. Radiology 233: 129-138. [Crossref]

Copyright: (C2015 Manzini R. This is an open-access article distributed under the terms of the Creative Commons Attribution License, which permits unrestricted use, distribution, and reproduction in any medium, provided the original author and source are credited. 